\title{
Novel Therapeutic Options due to Autologous Blood Components - Exemplified by Autologous Platelet Gel
}

\author{
D.F.M. Kuhn ${ }^{\mathrm{a}}$ \\ H. Braun ${ }^{a}$ \\ B. Fengler ${ }^{\mathrm{a}}$ \\ U. Taborski ${ }^{b}$ \\ G. Hempelmann ${ }^{a}$ \\ ${ }^{a}$ Abteilung Anaesthesiologie, Intensivmedizin, Schmerztherapie, Universitätsklinikum Gießen und Marburg, Standort Gießen, \\ ${ }^{b}$ Deutsche Gesellschaft für Humanplasma, Blut- und Plasmazentrum Koblenz, Germany
}

\section{Key Words}

Autologous platelet gel · Growth factors · Chronic wounds . Blood components · Apheresis

\section{Summary}

Autologous platelet gel (APG) was developed in the early 1970s as a byproduct of the so-called multi-component apheresis. APG is a matrix composed of fibrin and platelets, and was initially used as a wound sealing. Due to the effects of both thrombin and calcium, the platelets aggregates, resulting in a release of several growth factors. There is clinical evidence that the growth factors released enhance wound healing by stimulating tissue vascularity due to an increased rate of angiogenesis. Apart from that, APG acts hemostatic and causes a lymphatic sealing This effect leads to less seroma and thus to less pain postoperatively. The intraoperative production of APG for local application and as source of growth factors which serves as promoters of wound healing is part of the perioperative autologous hemotherapy and has to meet the legal regulations in Germany. The 12th amendment of the German Drug Law and the latest revision of the German Transfusion Act have aggravated the legal requirements for the production and application of autologous blood products. It is predominant regarding the legal question whethe or not one has to account those procedures as drug production in accordance to the German Drug Law. If one has to account, it is quite obvious that most of the German hospitals cannot meet the legal requirements of an intraoperative drug production. Because the German legislator has so far not defined a clear legal frame for novel perioperative autologous blood products, this could lead to the end of use of those techniques in our clinical routine. Thus, leading to the situation that no 'evidence class 1 study' will be conducted in order to investigate safety and efficacy of these novel procedures. The concept of the 'near patient unit' is new and therefore clinically not yet established. For perioperative autologous hemotherapy this concept defines the minimum legal requirements for a safe production and application of autologous blood products, out side of the scope of both, the German Drug Law and the German Transfusion Act, but still in accordance with the most recent guidelines on hemotherapy, as published by the Federal Medical Association (Bundesärztekammer). The legal end points are: no distribution to a third party, a strict personal identity for the production and application, exertion only by qualified persons, and an immediate connection to the planned operation as part of the method. The German legislator should modify both, the German Drug Law and German Transfusion Act in a way, to provide a legal certainty for the use of the perioperative hemotherapy.

\section{Schlüsselwörter}

Autologes Thrombozyten-Gel · APG · Wachstumsfaktoren · Wundheilungsstörungen · Blutkomponenten · Apherese

\section{Zusammenfassung}

Autologes Thrombozyten-Gel (APG) wurde in den frühen 1970er Jahren des letzten Jahrhunderts als Nebenprodukt der Multikomponentenapherese entwickelt. APG ist eine Matrix aus Fibrin und aggregierten Thrombozyten, welche initial nur als Wundverschluss eingesetzt wurde. Daneben werden aufgrund der durch Thrombin und Kalzium bedingten Thrombozytenaggregation im Gel Wachstumsfaktoren freigesetzt. Es gibt klinische Hinweise darauf, dass diese Wachstumsfaktoren die Wundheilung beschleunigen, indem die Gewebevaskularisierung durch eine erhöhte Angiogeneserate verbessert wird. Daneben wirkt APG hämostatisch und bewirkt einen lymphatischen Verschluss. Dieser Effekt vermindert nicht nur die Serombildung in den Wunden, sondern reduziert auch das postoperative Schmerzniveau. Die intraoperative Herstellung von APG zum Zwecke der lokalen Anwendung als Quelle von Wachstumsfaktoren, die der Förderung der akuten und chronischen Wundheilung dienen, ist Teil der so genannten perioperativen autologen Hämotherapie und unterliegt zunächst deren rechtlichen Rahmenbedingungen. Durch die 12. Novelle des Deutschen Arzneimittelgesetzes (AMG) und die Revision des Deutschen Transfusionsgesetzes (TFG) wurden die rechtlichen Anforderungen für die Herstellung und Anwendung autologer Blutprodukte deutlich verschärft. Für die Herstellung von APG ist es entscheidend, ob es sich hierbei um eine Arzneimittelherstellung im Sinne des AMG handelt. Falls ja, ist es unschwer nachzuvollziehen, dass die meisten operativen Abteilungen deutscher Krankenhäuser nicht in der Lage sind, die rechtlichen Rahmenbedingungen einer intraoperativen Arzneimittelherstellung zu erfüllen. Leider hat der Gesetzgeber es bisher versäumt, für diese neuen Verfahren klare rechtliche Rahmenbedingungen zu definieren. Dies kann für Deutschland nicht nur das faktische Ende der klinischen Anwendung perioperativer autologer Blutkomponententherapien bedeuten, sondern auch einen Durchführungsstopp der geforderten kontrollierten Studien der Evidenzklasse I zum Nachweis klinischer Sicherheit und Effektivität bewirken. Das Konzept der "near patient unit» ist neu und daher klinisch bisher noch nicht etabliert. Es definiert für die perioperative autologe Hämotherapie die rechtlichen Mindestvoraussetzungen nach denen APG gemäß der Hämotherapierichtlinien der Bundesärztekammer sicher hergestellt und angewendet werden kann, und zwar außerhalb des Geltungsbereiches von AMG und TFG. Diese sind: kein "In Verkehr bringen» an Dritte, eine strikte Personenidentität bei der Herstellung und Anwendung, die Ausübung ausschließlich durch zur Ausübung der ärztlichen Heilkunde befugte Personen und ein unmittelbarer Zusammenhang mit der Operation als Bestandteil der Methode. Durch Anpassungen des AMG und TFG sollte der Gesetzgeber rechtlich einwandfreie Rahmenbedingungen schaffen, damit für die klinischen Anwender bei der Durchführung der perioperativen autologen Hämotherapie Rechtssicherheit geschaffen wird.

\begin{tabular}{ll}
\hline KARGER & @ 2006 S. Karger GmbH, Freiburg \\
Fax +49 7614520714 & Accessible online at: \\
$\begin{array}{l}\text { E-mail Information@Karger.de } \\
\text { www.karger.com }\end{array}$ & www.karger.com/tmh
\end{tabular}


Theoretical Basics, Experimental Data, Clinical Results

\section{Theoretical Basics}

The concept of applying autologous platelet gel (APG) was developed in the early 1970s, when multicomponent apheresis was available in medicine [1,2]. Meanwhile, different producers of medical devices manufactured several devices (e.g.: Angel ${ }^{\circledR}$ Sorin-Group, Milano, Italy; Magellan ${ }^{\circledR}$, Medtronic, Düsseldorf, Germany), which are CE-marked and used within the European market to produce APG. In these devices, the production cycle is almost fully automated, and in principle, two components are required to facilitate the production of APG - on the one hand, a preferably high number of platelets and, on the other hand, autologous thrombin used to activate those platelets. The production cycle can be described as follows.

During the apheresis process, whole blood drawn from the patient (between 40 and $180 \mathrm{ml}$ ) and mixed with an anticoagulation agent (sodium citrate, ACD-A) is separated by centrifugation into three different fractions, namely the red blood cell (RBC), a platelet-poor plasma (PPP), and a platelet-rich plasma (PRP) fraction. Compared to baseline, the centrifugation causes a 5- to 6-fold increase in the number of platelets. Thus, PRP obtained from patients with a normal platelet count, possess more than 1 million platelets/ $\mu$ PRP. Due to production process used, PRP also contains white blood cells (fig. 1).

Mixing the PPP with alcohol and calcium in the presence of beads with negatively charged surfaces derives autologous thrombin. On activation with thrombin/calcium, the platelets interdigitate with the forming fibrin web, thus developing a gel with the release of ingredients of their alpha-, and betagranules. The length of the production cycle depends on the blood volume processed and totals to $47 \mathrm{~min}$ on average. The volume of APG obtained is about $10 \%$ of the total blood volume processed.

Apart from various tissue growth factors, highly active vasoconstrictors, including thromboxane and serotonin, are released from the platelets. Although at least 15 different growth factors could be identified in the PRP up to now, the predominant growth factors are the platelet derived growth factor (PDGF), the transforming growth factor (TGF), and the epithelial growth factor (EGF) [3].

PDGF consists of three subtypes (PDGFaa, PDGFbb, PDGFab). These factors are the main switches to initiate wound healing by stimulating both undifferentiated stem cells and endothelial cells to cell division, thereby activating angiogenesis [4-7]. TGF consists of two subtypes (TGF-b1, TGF-b2), which stimulate several mesenchymal stem cells within the connective tissue. EGF stimulates cell division, angiogenesis, and the activity of collagenases. However, for all growth factors the detailed mode of action is not clear yet.
Table 1. Wound incidence according to etiology in Europe, 2001: Medtech Inside Wound management 2003

\begin{tabular}{lll}
\hline Wound type & $\begin{array}{l}\text { Incidence } \\
\text { per 10,000 }\end{array}$ & $\begin{array}{l}\text { Annual growth } \\
\text { rate, \% }\end{array}$ \\
\hline Surgical wounds & 423 & 2.1 \\
Traumatic wounds & 62 & 1.4 \\
Burns & & \\
$\quad$ Outpatient care & 42 & 0.5 \\
$\quad$ Inpatient treatment & 1.8 & 0.7 \\
Pressure ulcers & 52 & 5.2 \\
Venous ulcers & 30 & 5.3 \\
Arterial/diabetic ulcers & 24 & 3.2 \\
Amputations & 1.5 & 0.5 \\
\hline
\end{tabular}

\section{Therapeutic Angiogenesis by APG}

The healthy body controls angiogenesis through a series of stimulators and inhibitors. The concept of therapeutic angiogenesis aimed at locally applying growth factors in excess to override existing inhibitors, thus leading to the clinical effect of a stimulated wound healing [8]. Whereas angiogenesis is activated by several growth factors (vascular endothelial growth factor (VEGF); PDGF, TGF, EGF), endogenous factors inhibit angiogenesis. Those factors are IFN- $\alpha / \beta$, the tissue inhibitors of metalloproteases (TIM-1, TIMP-2, TIMP-3) as well as angiostatin and endostatin, which are proteolytic decomposition products of proteins (antithrombin, plasminogen, collagen XVIII). The proteins themselves exhibit no anti-angiogenetic activity [9].

There is evidence that patients with impaired capacity for wound healing (obese patients, diabetic patients, atherosclerotic patients, patients with chronic obstructive pulmonary disease) will benefit from the prophylactic application of APG in both acute wounds and chronic wounds. There is a need to develop successful therapies to treat acute and chronic wounds since the number of patients affected by those clinical conditions increases year by year (table 1).

\section{Experimental Data}

In their in vitro study using sections of bovine aorta, Yonce et al. [10] could demonstrate a significantly enhanced growth of new vessels within 7 days when APG instead of normal basal medium was applied. The same group investigated the effect of APG on epidermal migration and full thickness wound closure in a porcine model [11]. Wound size was measured 14 and 28 days after application. Treatment with APG decreased the average wound size on day 14 by $37 \%$ and on day 28 by $63 \%$. However, published results from experimental studies on this topic are not consistent.

In our own study (explorative, prospective, double-blind) in rabbits (white New Zealand rabbits), we were also not able to 


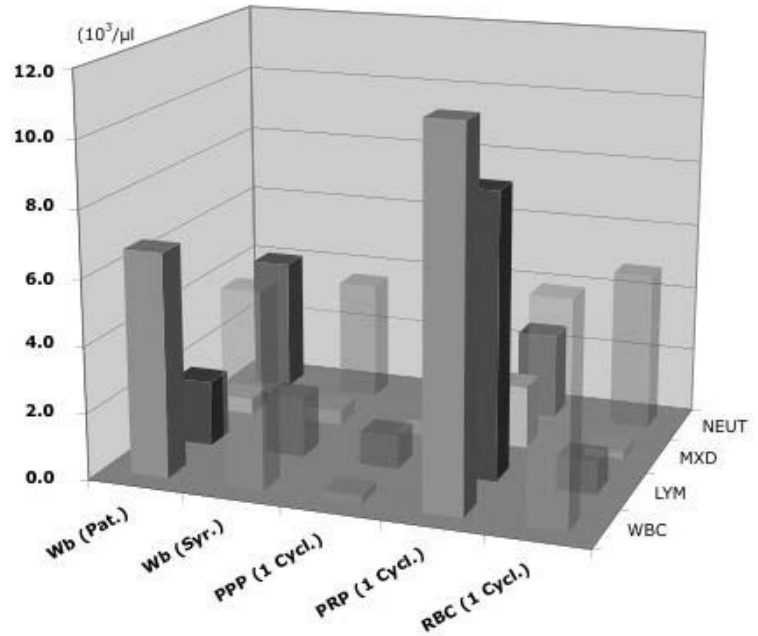

Fig. 1. Rate of white blood cells (WBC) within the three fractions obtained by multicomponent apheresis from whole blood, produced using the Angel ${ }^{\circledR}$.

$\mathrm{Wb}(\mathrm{Pat})=$ Whole blood:patient; $\mathrm{Wb}(\mathrm{Syr})=$ whole blood:syringe $; \mathrm{LYM}=$ Lymphocytes; MXD = mixed cells; NEUT = neutrophilic granulocytes .

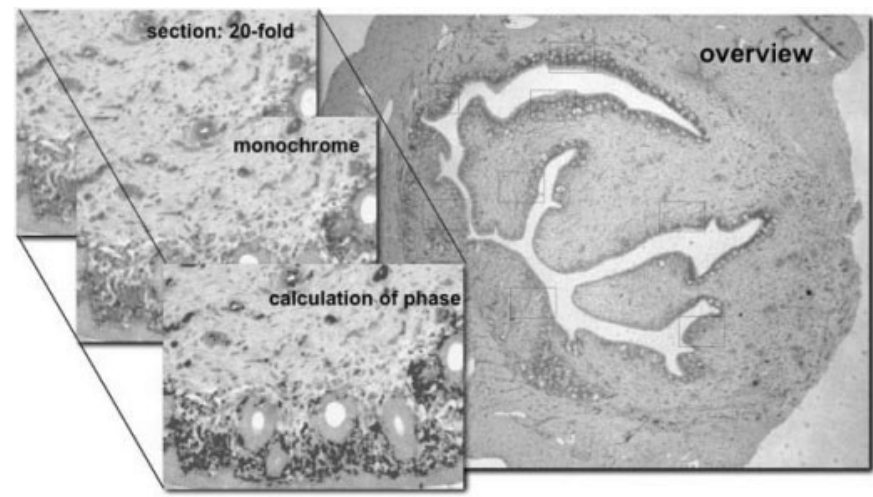

Fig. 2. Steps for the digital analysis of immunohistochemically stained tissue slides of a rabbit uterus.

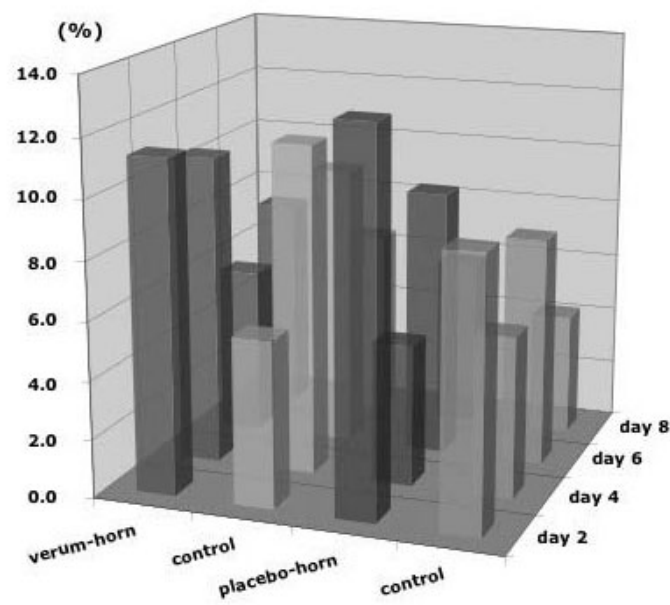

Fig. 3. Percentage of endothelial cells of vessels within the endometrium of the rabbit uterus 2, 4, 6 und 8 days after a single application of APG. Verum horn compared to control horn. show a clear therapeutically effect of APG on angiogenesis. In this study we investigated the effect of a single application of APG on the percentage of vessel endothelial cells within the endometrium of the uterus. Our hypothesis was a continuous increase of the percentage of those cells in the treated horn (verum) of the uterus, compared to both the second horn (control) of the same animal and the control animal. The peak of the vessel formation was expected 8 days after APG application. The experimental design was as follows.

Surgical application of APG into the cavity of the right horn of the uterus was performed while the animals were put under general anesthesia. Thereafter, the animals were divided into four groups and killed 2, 4, 6, and 8 days after the application of APG. The tissue samples were initially stored in formalin. Afterwards the tissue samples were coated with paraffin wax, and tissue slides of $5 \mu \mathrm{m}$ were prepared. The staining was carried out by an immunohistochemical method (alkaline phosphatase antialkaline phosphatase (APAAP) technique) using the vimentin antibody (1:100) which is specific for endothelial cells of vessels. Eight colored pictures (magnification 20x) of different areas were taken from every stained tissue sample using a digital light microscope (tissue area per picture 91,000 $\mu \mathrm{m}^{2}$ ). Thereafter, all colored pictures were converted into monochrome pictures, and the percentages of endothelial cells were calculated (50-135 nm phase) using a computerized software (analySYS, Docu. 3.2; fig. 2).

As opposed to our expectations, in all animals only a physiologic and cyclical pattern of up to $15 \%$ endothelial cells was found. An effect of APG on vessel formation within the uterus could not be demonstrated (fig. 3). This might be explained by the fact that either there was no effect of APG on the vessel formation at all or that an intact epithelial layer prevents growth factors from penetrating into the endometrium.

\section{Clinical Results}

Maxillofacial surgeons published the majority of clinical studies on APG. Especially the group of Marx et al. (University of Miami School of Medicine) could demonstrate an increased osteogenesis after application of APG [12]. Even in certain orthopedic operations, the local application of APG was shown to increase bone formation (traumatic loss of bone mass, spondylodesis). However, the results obtained in maxillofacial and orthopedic surgery are contradictory. While Franchini et al. [14] could show an osteoinductive effect of APG in bone-reconstructive maxillofacial surgery, such an effect could not be approved in orthopedic surgery so far. In two independent studies Carreon et al. [15] and Castro [16] deny any measurable effects of APG on osteogenesis in their patients.

For acute and chronic wound healing the published results are more consistent. Serra et al. [17] could show that local appli- 
cation of APG increased wound healing in chronic wounds. The same was true for acute wounds as shown by Kent [18] who demonstrated an enhanced acute wound healing in patients prone to secondary wound healing.

However, it must be emphasized that the majority of the studies published so far does not meet the requirements of socalled evidence class 1 studies. To finally assess the possible effectiveness of APG in promoting acute and chronic wound healing, such evidence class 1 studies must be done. In Germany, however, the implementation of such clinical studies is considerably hampered by the new legal regulations, making their realization nearly unfeasible from practicable point of view. As a consequence to this clinical situation, the concept of the 'near patient unit' (NPU) was developed.

\section{Legal Basis for the Production and Application of Autologous Platelet Gel in Germany}

Perioperative autologous hemotherapy is controlled by the German Drug Law (Arzneimittelgesetz; AMG) [19], the German Transfusion Act (Transfusionsgesetz; TFG) [20], and the most recent guidelines on hemotherapy (RiLis) as published by the Federal Medical Association (Bundesärztekammer; BÄK) [21]. According to §2 AMG (definition of drugs), and $\S 4$, chapter 2 AMG (other definitions) in association with $\$ 2$ TFG (definitions), APG is a drug because of his character of a blood preparation and source of growth factors thought to promote wound healing. Everybody who wants to produce a drug shall require authorization ( $\$ 13$, chapter 1 , first sentence AMG (manufacturing authorization), by the competent authority. According to $\$ 13$, chapter 1, third sentence, the need for authorization is bound to the matter of fact 'distribution to others'. If the person manufacturing the drug is the same as the person using it, one does not require authorization. Nevertheless, according to $\$ 67$, chapter 1 AMG (general obligation of notification) one is obligated to notify the local authorities, with the legal consequence that the competent authority will supervise the whole production cycle.

With the 11th amendment of the AMG from August 21, 2002, a new paragraph was included into this law which defines exceptions from the scope of the AMG. According to $\S 4$ a, chapter 3 AMG (exceptions from the operative range), the AMG will not govern the production and application of APG, provided that both takes place under the unshared professional responsibility of a qualified person and the method applied is an element of the surgical procedure. This is true even if the APG will be stored for the length of the operation.

Even though the drawn of autologous blood as raw material could be considered as an independent process, it remains an integral element of the surgical procedure. This circumstance is in principle similar to the intraoperative blood salvage which is neither classified as a process independent from the surgical procedure nor defined as drug production.

If the AMG is not implemented, this applies automatically for the TFG as well $[22,23]$. A preparation which contains autologous blood or autologous blood components is considered only as a blood product in the legal sense of the TFG when it is classified as a drug.

This legal conception applies only for the intraoperative production of APG as part of the surgical procedure where the surgeon applies a product which was produced by him and not distributed to others. Without a strict personal identity in production and application of APG, the AMG comes into effect, thus requiring authorization by the competent authority.

Independent from the question of a possible drug production, APG still remains a blood product and has to be considered as part of the perioperative autologous hemotherapy. Everybody who applies APG has to ensure both product safety and quality. According to the prevailing case law in Germany, those goals are ensured by strictly following the RiLis as published by the BÄK [21] during production and application of APG.

Meanwhile, in Germany these RiLis are considered as lawlike standards. In their most recent amended version an obligation for quality assurance was defined for the first time, and consequently all transfusion procedures have to be integrated into the quality assurance management of the individual hospital.

This means that the physician producing APG acts also as a licensed physician for his treatment unit and has to be a member of the transfusion commission. He has to define a quality manual including standard operating procedures (SOPs) and to conduct training courses for co-workers if needed. In this respect the production of APG does not differ from the production of other autologous products. Although this production takes place outside of the legal scope of AMG and TFG, one has to comply with the legal requirements for the production of blood or blood components as lined out in $\$ 15$ TFG (July 1, 1998, amended on February 15, 2005). This is especially true with regard to certain infection markers. According to the RiLis the measurement for HIV as well as HBV and HCV antibodies is compulsory in all patients undergoing the production of APG.

Only the implementation of those RiLis by the physician constitutes legally a so called: 'vitiate assumption' in a way that APG was produced according to $\S \S 12,18 \mathrm{TFG}$, thus ensuring the 'state of the art'. This assumption is rather important for the physician since he will be 'immune for liability' in case of being sued by somebody.

Regretfully, within the latest amendment of $\$ 28$ TFG, perioperative autologous methods were not classified as exceptions from the scope of application. Homeopathic autologous products and autologous blood products for immune therapy are listed. Widely used autologous methods such as blood salvage are not. This seems to be out of all reason. 
Table 2. Administrative provisions for the conduct of clinical trials according AMG the 6th section 'Protection of the Human Being during the Clinical Trial', §40 et sqq, of the AMG (12th amendment, April 2004)

Implementation of GCP in all studies, including investigator-initiated studies

Extended approval procedures for studies:

Approval by ethical committee

Approval by supreme federal office (PEI)

Allocation of a study number (EudraCT database)

Definition of a 'sponsor' (natural or legal person)

Exception: (noninterventional studies)

Table 3. Essential components of the quality manual NPU

Representation of the structures (structure of the department, organisational structure, personnel structure, SOPs)

Regulatory aspects

Demonstration of material and data flow (look-back documentation)

Documentation contractual regulations (patient agreement, impenetration agreement surgeon/anesthetist, utility supply contracts, contracts with consultants)

\section{Conducting Clinical Studies}

According to the EU directive 2001/20/EC from April 4, 2001 on the approximation of the laws, regulations and administrative provisions of the member states relating to the implementation of good clinical practice (GCP) in the conduct of clinical trials on medicinal products for human use, the AMG was amended on July 30, 2004 (12th amendment AMG, implemented on August 6, 2004), thereby putting the international directives on GCP into national legislation. Those directives have to be applied in all clinical trials on drugs within the Europe.

The AMG controls all clinical trials on drugs. A clinical trial in accordance with $\$ 40 \mathrm{ff}$ AMG (general preconditions) is:

... any investigation in human subject intended to discover or verify the clinical, and/or pharmacological effects of drugs and/or to identify any adverse reactions and/or to study adsorption, distribution, metabolism and excretion with the object of ascertaining its safety and/or efficacy.

In this paragraph one also find a definition of a sponsor:

... an individual, company, institution or organization which takes responsibility for the initiation, management and/or financing of a clinical trial in human subject.

The definition of a sponsor which has to be a located in the EU is mandatory for conducting a clinical trial. It is important to emphasize that the sponsor has to assume liability and has the overall responsibility regarding all aspects of the trial (e.g. implementation of GCP as well as implementation of specific documentation and notification requirements). A principal investigator must be solely defined in multicenter studies.

Furthermore, a clinical trial on drugs has to be approved by both the local ethical committee and the supreme federal office (Paul-Ehrlich-Institut; PEI). The same applies for intended modifications of the study design if possible effects on safety, significance, and harmlessness of the study drug are to be suspected or major organizational measures are affected. Permission can be cancelled (table 2).

Although the EU directive 2001/20/EC formally allows member states to define special forms of relief in conducting noncommercial studies, those facilities are not defined in the 12th amendment of the AMG. The only exception is defined for noninterventional studies in which simplified approvals still apply.

Noninterventional studies meet the criteria of an evidence class 1 study by no means, thus ignoring the need for that kind of clinical trials to implement novel and innovative procedures. Neither will data derived from noninterventional studies be accepted for publication in leading journals, nor are those data qualified to adjust the state of art for both established and novel methods. Furthermore, health insurance funds will not include novel autologous methods into the list of services covered until their therapeutic efficacy is proven by prospective and controlled clinical studies.

Consequently, in order to conduct commercial trials, and/or investigator-initiated studies (noncommercial studies), scientists are not only obliged to define a responsible sponsor but also to spend much more effort, money, and time compared to recent years.

Taking into consideration that hospitals have to operate under increasingly difficult conditions, hardly any hospital can meet these standards. This might lead to the factual end of using innovative autologous therapeutic concepts in Germany.

\section{Legal and Organisational Basis of a 'Near Patient Unit' (NPU)}

The concept of a NPU to deliver perioperative autologous techniques was developed to define boundary conditions under the current legislation under which innovative autologous products can be produced and applied in a safe, efficient and cost-effective way. It is fundamental to distinguish perioperative from preoperative techniques because a NPU is solely designed to produce and apply perioperative autologous products, regardless whether they are already established or are new and innovative. Such techniques are addressed as 'near patient'. In opposite to the 'near patient' techniques, blood banks and predonation units apply methods on a high level and in a safe and standardized manner. Since all autologous products produced are separated from the patient and stored up to several weeks before being re-transfused to the donor, one can classify those units as 'afar patient'. 


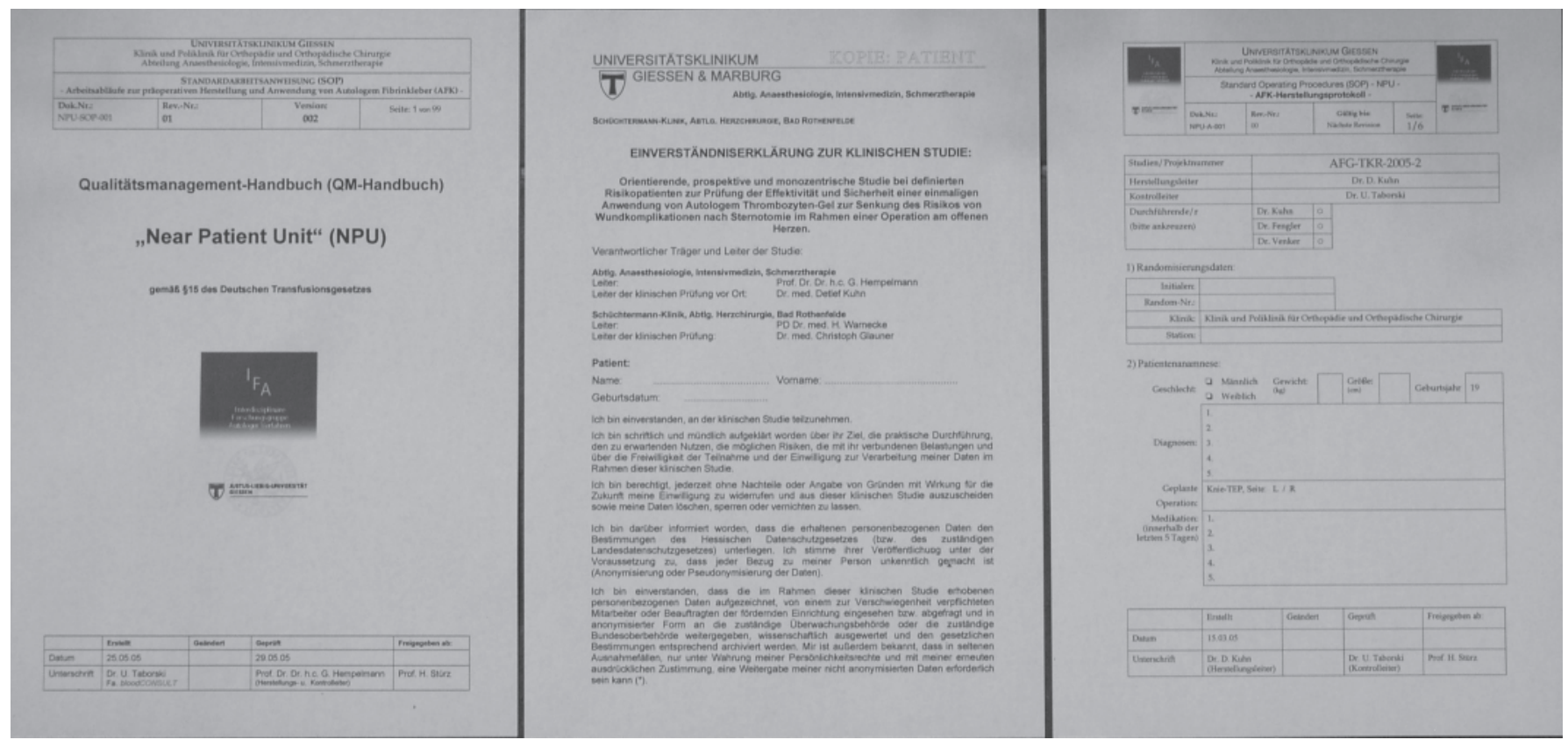

Fig. 4. Documents for quality assurance in a 'near patient unit' (NPU).

In order to ensure product safety and quality for predonated blood, the RiLis reflect on this technique and provide a detailed account of all required boundary conditions, thus establishing a legal certainty for the user. This is not the case for innovative, autologous therapeutic concepts such as the use of autologous fibrin glue and APG. Such concepts still lack a clear definition of the 'state of the art'. Since such criteria can be defined only by data derived from controlled studies, the new definition of $\$ 40 \mathrm{ff} A M G$ endangers the scientific work to further develop such products. One easily comprehends that autologous blood salvage techniques could not have been established as a valuable and acknowledged clinical tool under the actual legal conditions.

Consequently, the concept of an NPU defines organizational and legal boundary conditions under which autologous blood products can be produced and applied outside of the scope of the AMG. Even though outside of the validity of AMG and TFG, the concept of the NPU ensures that innovative autologous techniques still will be used in clinical routine and allows for conducting clinical trials within proved and tested structures.

The NPU ensured product safety and quality of their autologous products by strictly following the RiLis (e.g. prove for efficacy, testing of infection markers, implementation by a qualified person, established system for quality assurance).

The main strategic goals of the NPU concept are supply of autologous products at the right time (service and organization) and appropriate components (transfusion medicine) in adequate quantity (self-sufficient); moreover, the products should be free of side effects (product safety), and with respect to their therapeutic goal cost-effective.
For this reason one has to embed the NPU into the quality assurance management of the individual hospital (transfusion commission, hygiene commission, drug commission, therapeutic guidelines). Consequentially and in accordance with $§ 15$ TFG (quality assurance), only CE-certified devices and disposables should be applied within a NPU. Furthermore, one has to examine and to document the expert knowledge of the qualified person. Due to the draft of standardized instructions (quality manual, SOPs), a consistent documentation of the production process is ensured (fig. 4, table 3 ).

The application of perioperative autologous products within the NPU is always part of the surgical procedure. This is the major advantage compared to 'afar' methods. The choice of methods and products applied is based on the individual therapeutic strategy of the planned operation and carried out by the surgeon. For the first time, an undivided responsibility is guaranteed, covering production, quality assurance as well as application. At the same time, the surgeon is able to evaluate the therapeutic success. If necessary, he can modify the therapeutic scheme without loss of time. This will consequently lead to a better quality of care.

\section{Conclusion}

For more than 30 years APG is used in clinical centers, despite the lack of scientific proof of efficacy with respect to several proposed therapeutic goals. The use of APG in order to promote acute and chronic wound healing seems to be the most promising approach since many papers report consistently about a therapeutic efficacy. Unfortunately, most of the pub- 
lished work does not meet the requirements of an evidence class 1 study. Those studies are indispensable to prove the therapeutic efficacy of APG. The legal boundary conditions referring to both the production and application of autologous products as well as the implementation of clinical trials as lined out in the actual AMG have led to a 'de facto' end of the clinical use of APG, thereby terminating the scientific debate on these innovative techniques. Within the scope of the actual AMG and TFG, new therapeutic concepts can be developed only by investing time and raising an enormous expense.

The concept of the NPU is innovative and describes a way out of this purely legal dilemma. This concept is new and thus not clinically established yet. Conceptually, the NPU possesses remarkable advantages compared to traditional units which produce 'afar patient' products preoperatively. Just as the traditional units, the NPU will be established according to highest standards. At the same time, the NPU is able to develop therapeutic strategies and to conduct clinical trials without spoiling the requirements concerning product safety and quality, as demanded by the legislator.

Independent of this concept, one should demand from the German legislator to amend the AMG and TFG in a way to define clear legal boundary conditions for the innovative autologous procedures.

\section{References}

1 Hughes AD, Clunn GF, Refson J, Demoliou-Mason C: Platelet-derived growth factor (PDGF): Actions and mechanisms in vascular smooth muscle. Gen Pharmac 1966;27:1079-1089.

-2 Zimmermann R, Jakubietz R, Jakubietz M, Strasser E, Schlegel A, Wiltfang J, Eckstein R: Different preparation methods to obtain platelet components as a source of growth factors for local application. Transfusion 2001;41:1217-1223.

3 Snyder EL, Calhoun BC: Topical platelet growth factor therapy: of lotions and potions (Editorial). Transfusion 2001;41:1186-1189.

4 Crovetti G, Martinelli G, Issi M, Barone M, Guizzardi M, Campanati B: Platelet gel for healing cutaneous chronic wounds. Transfus Apheresis Sci 2004;2:145-151.

5 Tischler M: Platelet rich plasma. The use of autologous growth factors to enhance bone and soft tissue grafts. N Y State Dent J 2002;68:22-24.

6 Man D, Plosker H, Winland-Brown JE, Saltz R: The use of autologous platelet-rich plasma (Platelet gel) and autologous platelet-poor plasma (fibrin glue) in cosmetic surgery. Plast Reconstr Surg 2001; 107:238-239.

7 Petrungaro PS: The use of platelet rich plasma with growth factors (autologous platelet gel) to enhance hard and soft tissue healing and maturation in the reconstruction of the maxillary pneumatized sinus. Contemp Periodontics Implant 2001;9:231-233.

$>8$ Augustin HG: Translating angiogenesis research into the clinic: the challenges ahead. Br J Radiol 2003;76:S3-10. $\checkmark$ Plate KH, Breier G, Risau W: Molecular mechanisms of developmental and tumor angiogenesis. Brain Pathol 1994;4:207-218.

10 Yonce L, Laudenbach A, Cariappa R, Fernandes B, Huang T: Platelet gel accelerates wound healing in vitro: European Tissue Repair Society, 2005, 15th Annual Meeting, Stuttgart, Poster presentation V28.

11 Yonce L, Huang T, Merte K: Enhanced epidermal migration and wound closure by autologous platelet gel in a porcine model. European Tissue Repair Society, 2005, 15th Annual Meeting, Stuttgart, Poster presentation V28.

12 Marx RE, Carlson ER, Eichstaedt RM, Schimmele SR Strauss JE, Georgeff KR: Platelet-rich plasma growth factor enhancement for bone grafts. Oral Surg Oral Med Oral Pathol Oral Radiol Endod 1998;85:638-646.

13 Slater M, Patava J, Kingham K, Mason RS: Involvement of platelets in stimulating osteogenic activity. J Orth Research 1995;13:655-663.

14 Franchini M, Dupplicato P, Ferro I, De Gironcoli M, Aldegheri R: Efficacy of platelet gel in reconstructive bone surgery. Orthopedics 2005;28: 161-163.

15 Carreon LY, Glassman SD, Anekstein Y, Puno RM: Platelet gel (AGF) fails to increase fusion rates in instrumented posterolateral fusions. Spine 2005;30: 243-246.

16 Castro FP: Role of activated growth factors in lumbar spinal fusions. J Spinal Disord Tech 2004;17: 380-384.
17 Serra M, Panizza R, Rivara G, Orecchia S, Libener R, Cattana E, Levis, A, Betta PG, Borzini P: The use of autologous platelet gel to treat difficult-toheal wounds: a pilot study. Transfusion 2004;44: 1013-1018.

18 Kent KJ: Promising results from a preliminary study of autologous platelet gel in face-lift surgery. Arch Facial Plast Surg 2001;3:251.

19 Gesetz über den Verkehr mit Arzneimitteln? (AMG) - Arzneimittelgesetz Bundesgesetzblatt. I Nr. 73 vom 15.12.2005 S. 3394.

20 Gesetz zur Regelung des Transfusionswesens (TFG) - Transfusionsgesetz in der Fassung vom 1.7.1998, zuletzt geändert durch Erstes Gesetz zur Änderung des Transfusionsgesetzes und arzneimittelrechtlicher Vorschriften vom 10.2.2005. Bundesgesetzblatt I 2005, S. 234.

21 Richtlinien zur Gewinnung von Blut und Blutbestandteilen und zur Anwendung von Blutprodukten (Hämotherapie) der Bundesärztekammer in der Fassung vom 04.08.2005. Bundesanzeiger 209a/ 2005.

22 Zimmermann R, Bender A, Eckstein R: Rechtliche Rahmenbedingungen der autologen Hämotherapie - Teil I. Bayr Ärztebl 2002;6:300-303.

23 Zimmermann R, Bender A, Eckstein R: Rechtliche Rahmenbedingungen der autologen Hämotherapie - Teil II. Bayr Ärztebl 2002;7:356-360. 